\title{
Simulasi Berbasis MEH untuk Pemodelan Distribusi Potensial Listrik dan Medan Listrik pada Isolator Porselen 20 kV
}

\author{
ASHADI AMIR NURHAKIM, ROBBY IKHSAN AR RASYID, WALUYO
}

Program Studi Teknik Elektro, Institut Teknologi Nasional

Email: ashadi.nurhakim.an@mhs.itenas.ac.id

Received 17 Agustus 2021| Revised 4 September 2021| Accepted 8 September 2021

\begin{abstract}
ABSTRAK
Isolator adalah suatu perlengkapan yang cukup berarti dalam saluran udara tegangan menengah. Distribusi potensial serta medan listrik di sekitar isolator ialah wilayah yang masih mendapat pengaruh sifat kelistrikan dari suatu muatan. Riset ini mengulas simulasi distribusi potensial serta medan listrik pada isolator tegangan menengah berjenis porselen berbasis metode elemen hingga (MEH). Metode ini digunakan agar memudahkan dalam mengukur pendistribusian potensial listrik dan medan listrik pada isolator karena merupakan salah satu metode numerik yang lebih praktis untuk memecahkan masalah elektrostatik. Dari hasil simulasi 3D diperoleh pola distribusi potensial listrik selalu mengikuti kontur dari isolator sedangkan untuk distribusi medan listriknya mencapai nilai tertinggi sebesar $5,3 \mathrm{kV} / \mathrm{cm}$. Sedangkan dari grafik distribusi medan listrik terlihat lebih jelas bahwa stress medan listrik yang besar terdapat pada daerah koneksi antara isolator dengan konduktor serta isolator dengan ground.
\end{abstract}

Kata kunci: Isolator Porselen, Medan Listrik, Metoda Elemen Hingga (MEH), Potensial Listrik.

\section{ABSTRACT}

An insulator is a fairly significant piece of equipment in a medium-voltage overhead line. The distribution of potential and electric field around an insulator is an area that is still affected by the electrical properties of a charge. This research reviews the distribution of potential and electric field simulations on porcelain-type medium-voltage insulators based on the finite element method (FEM). This method is used to make it easier to measure the distribution of electric potential and electric field on an insulator because it is one of the more practical numerical methods for solving electrostatic problems. From the 3D simulation results, the distribution pattern of the electric potential always follows the contours of the insulator, while the electric field distribution reaches the highest value of $5.3 \mathrm{kV} / \mathrm{cm}$. Meanwhile, from the electric field distribution charts, it is clearer that the large electric field stress is found in the area around the insulator with conductors and insulators with ground.

Keywords: Porcelain Insulator, Electric Field, Finite Element Method (FEM), Electric Potential. 


\section{PENDAHULUAN}

Isolator pada jaringan distribusi memiliki peran untuk mengisolasi antara bagian penghantar listrik dengan tanah/ground sehingga arus listrik dapat terisolir dan tidak terjadi hubung singkat dari bagian bertegangan tersebut menuju ke tanah (Tobing, 2012). Menurut data, penggunaan isolator pada transmisi dan distribusi kelistrikan merupakan hal yang penting dan akan selalu diperlukan di masa mendatang (Garinas, 2016).

Isolator outdoor yang digunakan di SUTM pada kondisi operasionalnya akan selalu menghadapi berbagai macam kondisi cuaca dan lingkungan. Pada umumnya masalah kontaminasi polutan banyak dialami oleh isolator outdoor dengan berbagai zat kontaminasi sesuai dengan kondisi lingkungan di sekitarnya (Pratiwi, 2013). Kontaminan di lingkungan sekitar isolator yang menempel pada isolator dalam jangka waktu lama akan membentuk lapisan tipis pada permukaan insulasi (Anwar, 2019). Konstanta dielektrik dari suatu bahan isolator dapat terpengaruh apabila terkontaminasi oleh zat lain yang menempel pada permukaan isolator tersebut. Hal ini akan berakibat pada berubahnya distribusi maupun nilai medan listriknya (Fahmi, Yulistya, Asfani, \& Afif, 2015).

Medan listrik yang tinggi pada bahan isolator dapat menyebabkan terjadinya partial discharge (corona). Membiarkan sistem isolasi pada stress medan listrik yang tinggi serta mengalami fenomena corona pada akhirnya dapat merusak sistem isolasi (Panjaitan, Sinaga, \& Purwasih, 2014). Corona berbahaya karena menyebabkan terjadinya reaksi kimia pada permukaan konduktor sehingga mengakibatkan losses dan kerusakan pada konduktor (Ogar, Bendor, \& James, 2017). Corona dapat terjadi apabila besar medan listrik melampaui besar gradien tegangan tembus udara yang bernilai sebesar $30 \mathrm{kV} / \mathrm{cm}$ (Saadat, 2004). Berdasarkan pengujian menggunakan standar IEC (IEC 61109, IEC 62217, IEC 60815 dan IEC 61466-1, -2) pada distribusi medan listrik yang dilakukan oleh Siemens terhadap isolator komposit yang diproduksinya, didapatkan hasil bahwa stress medan listrik pada keadaan normal cenderung mengalami peningkatan pada connection zone (daerah sambungan isolator dengan ground ataupun dengan konduktor) (Siemens, 2012).

Metode elemen hingga merupakan salah satu metode yang dapat digunakan untuk menghitung besar dan distribusi dari potensial listrik serta medan listrik. Metode ini akan menanalisis objek dengan bentuk yang kompleks dan rumit dengan cara membaginya menjadi sekumpulan-sekumpulan elemen kecil yang jumlahnya dapat mencapai ribuan. Pembagian objek ke dalam elemen-elemen kecil ini bertujuan untuk menyederhanakan perhitungan, namun dikarenakan jumlahnya yang begitu banyak menjadikannya sulit untuk dihitung secara manual. Hadirnya teknologi komputerisasi modern berupa software berbasis $\mathrm{MEH}$ dapat membantu memudahkan dalam penggunaan metode ini. Namun, kesalahan seperti kesalahan diskritisasi dan kesalahan perhitungan masih dapat terjadi dikarenakan metode elemen hingga merupakan metode numerik daerah diskrit dari struktur kontinu (Ghifari, Lazuardi, \& Somantri, 2017).

Berdasarkan latar belakang tersebut, permasalahan yang dikaji pada penelitian ini adalah bagaimana pola distribusi serta besar potensial listrik pada isolator porselen untuk jaringan distribusi tegangan menengah $20 \mathrm{kV}$ serta bagian mana pada isolator yang mengalami stress medan listrik yang besar atau bahkan hingga terjadi corona. Dari hasil penelitian dapat diketahui bagaimana kemampuan dari jenis isolator ini dalam mendistribusikan potensial listrik dan medan listrik. Oleh karena itu, software simulasi berbasis MEH pada penelitian ini digunakan bertujuan untuk mendapatkan pola distribusi serta besar potensial listrik dan medan listrik tersebut dengan praktis dan mudah. 


\section{METODOLOGI PENELITIAN}

\subsection{Diagram Alir Penelitian}

Penelitian diawali dengan studi literatur sebagai bahan referensi untuk penelitian ini. Kemudian dilanjutkan dengan mencari data-data spesifikasi dari isolator yang akan dimodelkan. Setelah didapatkan data yang lengkap, maka pemodelan isolator dilakukan dengan software berbasis CAD. Langkah selanjutnya setelah model 2D dan 3D isolator dibuat adalah proses simulasi yang dilakukan dengan menggunakan software berbasis MEH. Tahap terakhir dari penelitian ini yaitu menganalisis dan menyimpulkan hasil simulasi yang didapatkan. Diagram alir penelitian diperlihatkan pada Gambar 1 di bawah ini.

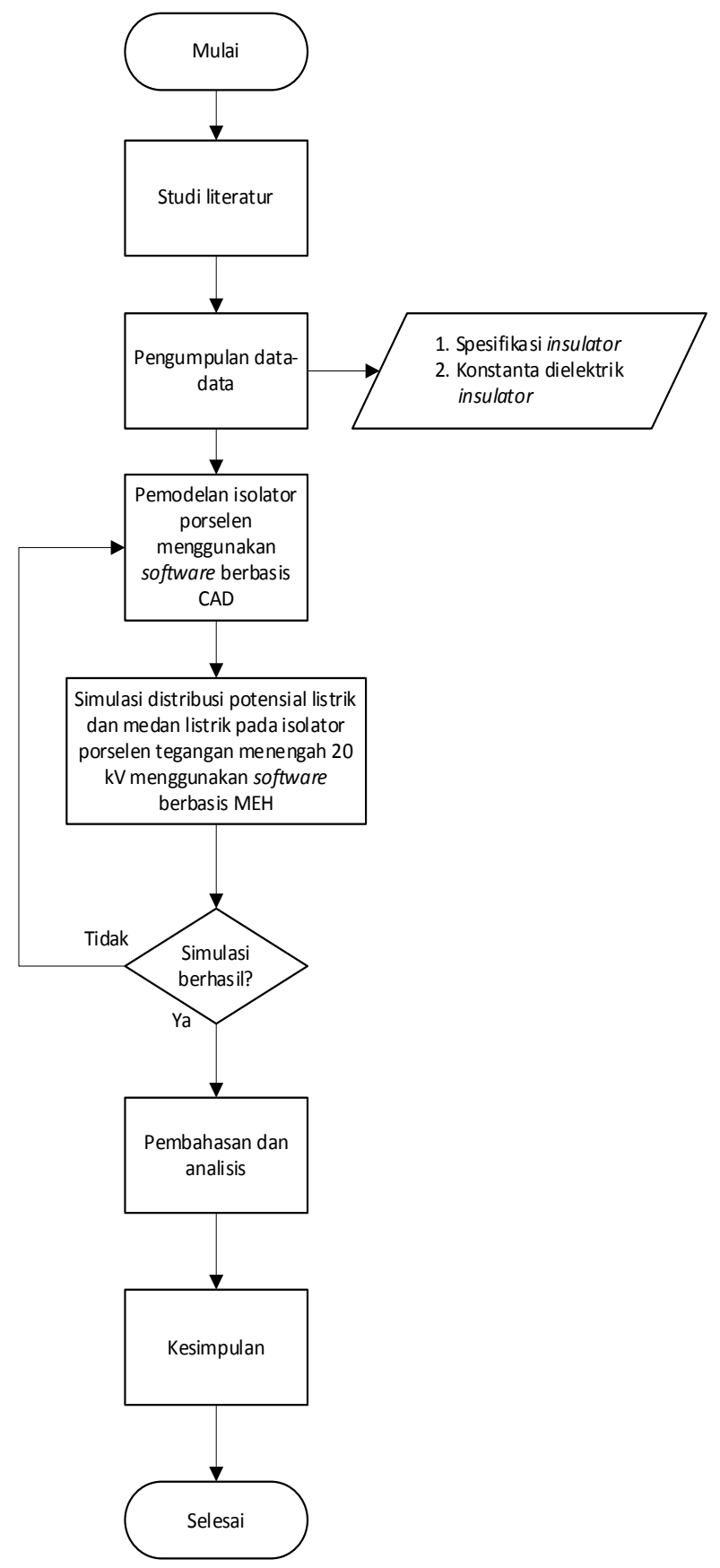

Gambar 1. Diagram Alir Penelitian 


\subsection{Spesifikasi Isolator}

Spesifikasi dari isolator porselen $20 \mathrm{kV}$ yang digunakan pada penelitian ini ditunjukkan pada Tabel 1 berikut:

Tabel 1. Spesifikasi Isolator Porselen

\begin{tabular}{|c|c|}
\hline Specification & Material \\
\hline Operating Voltage $[\mathrm{kV}]$ & 20 \\
\hline Spacing $(\mathrm{H})[\mathrm{mm}$ & 350 \\
\hline Diameter (D) [mm] & 180 \\
\hline Creepage Distance (L) [mm] & 400 \\
\hline Brand / Product Code & XDGE/ZS-20/10 \\
\hline Structure Insulator & Post \\
\hline Dielectric Constant & 6 \\
\hline
\end{tabular}

Nilai konstanta dielektrik pada isolator porselen adalah 6 (Changfu, et al., 2017) (Rosli, Othman, Jamail, \& Ismail, 2017). Gambar 2 menunjukkan gambar teknik isolator porselen tipe post dari produk XDGE dengan kode produk ZS-20/10 (General Electric Company, 2020).

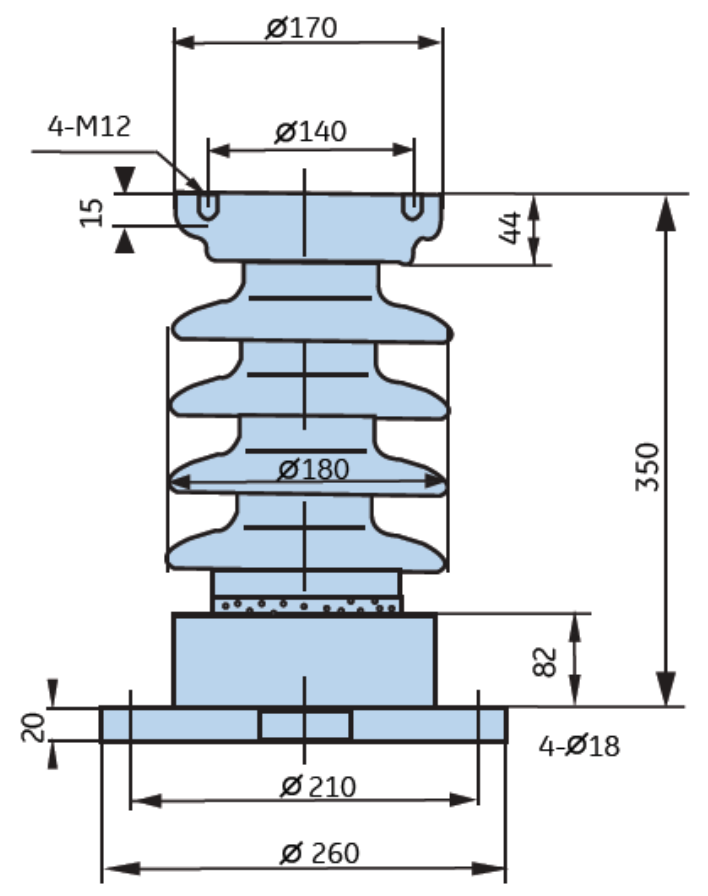

Gambar 2. Gambar Teknik Isolator Porselen Tipe Post

\subsection{Pemodelan 3D Isolator}

Pemodelan isolator dimulai dengan membuat model 2D isolator, lalu diubah kedalam bentuk 3D. Pemodelan ke dalam bentuk 3D dilakukan dengan menggunakan teknik revolve. 
Pemodelan 2D isolator dilakukan dengan mengikuti data spesifikasi isolator, mulai dari panjang, lebar, ketinggian, hingga konturnya. Mula-mula isolator hanya digambar setengah bagian, lalu model isolator yang telah dibuat dalam bentuk $2 \mathrm{D}$ diputar $360^{\circ}$ pada sumbu bagian tengah isolator sehingga menghasilkan model isolator 3D. Gambar 3 berikut merupakan proses pemodelan 2D isolator menggunakan software berbasis CAD tersebut.

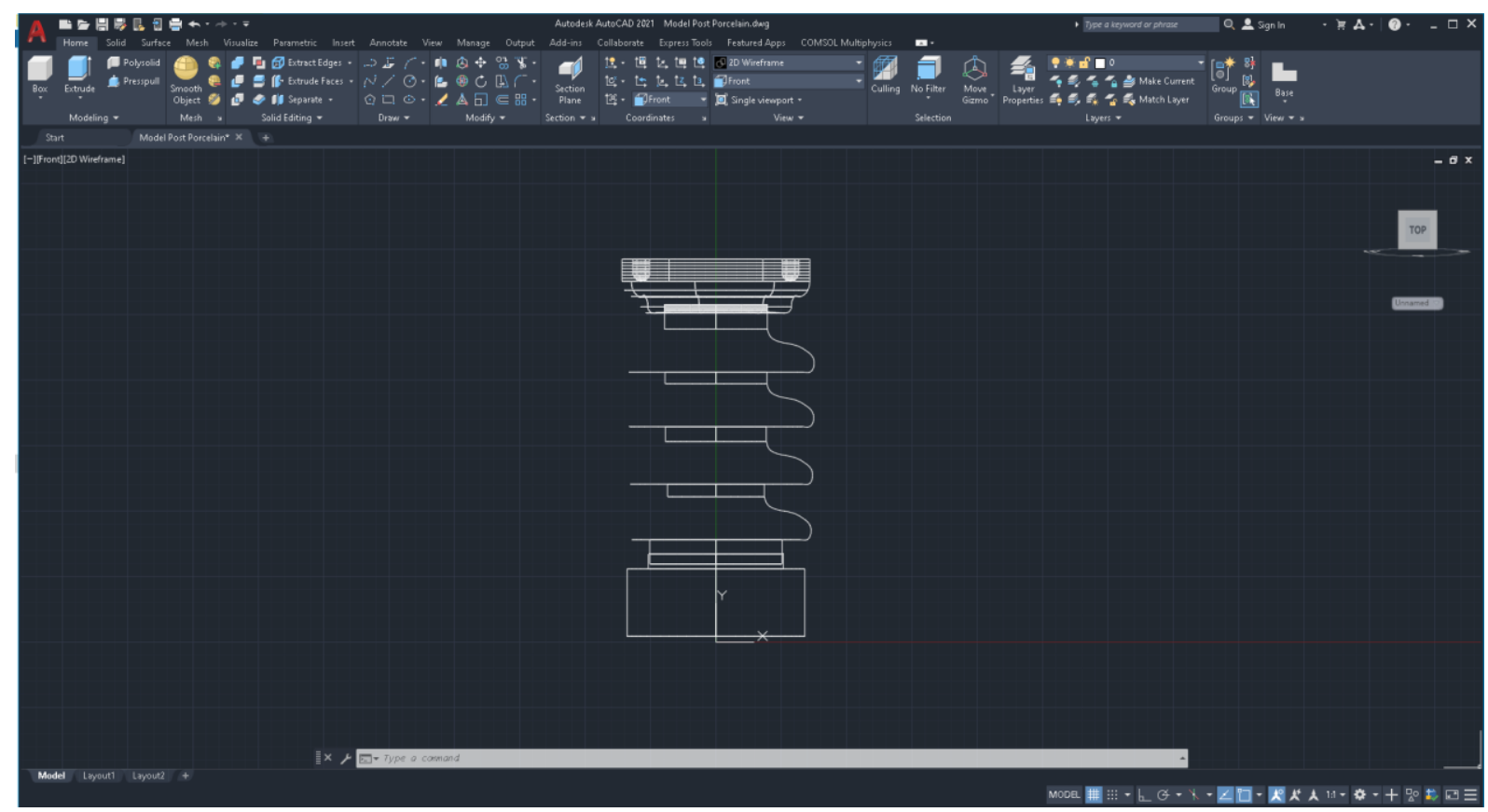

Gambar 3. Pemodelan 2D Isolator

Gambar 4 di bawah ini merupakan hasil revolve dari isolator 2D menggunakan software berbasis CAD sehingga terbentuk model 3D. Setelah pemodelan 3D isolator selesai, maka tahap selanjutnya adalah simulasi dengan menggunakan software berbasis $\mathrm{MEH}$.

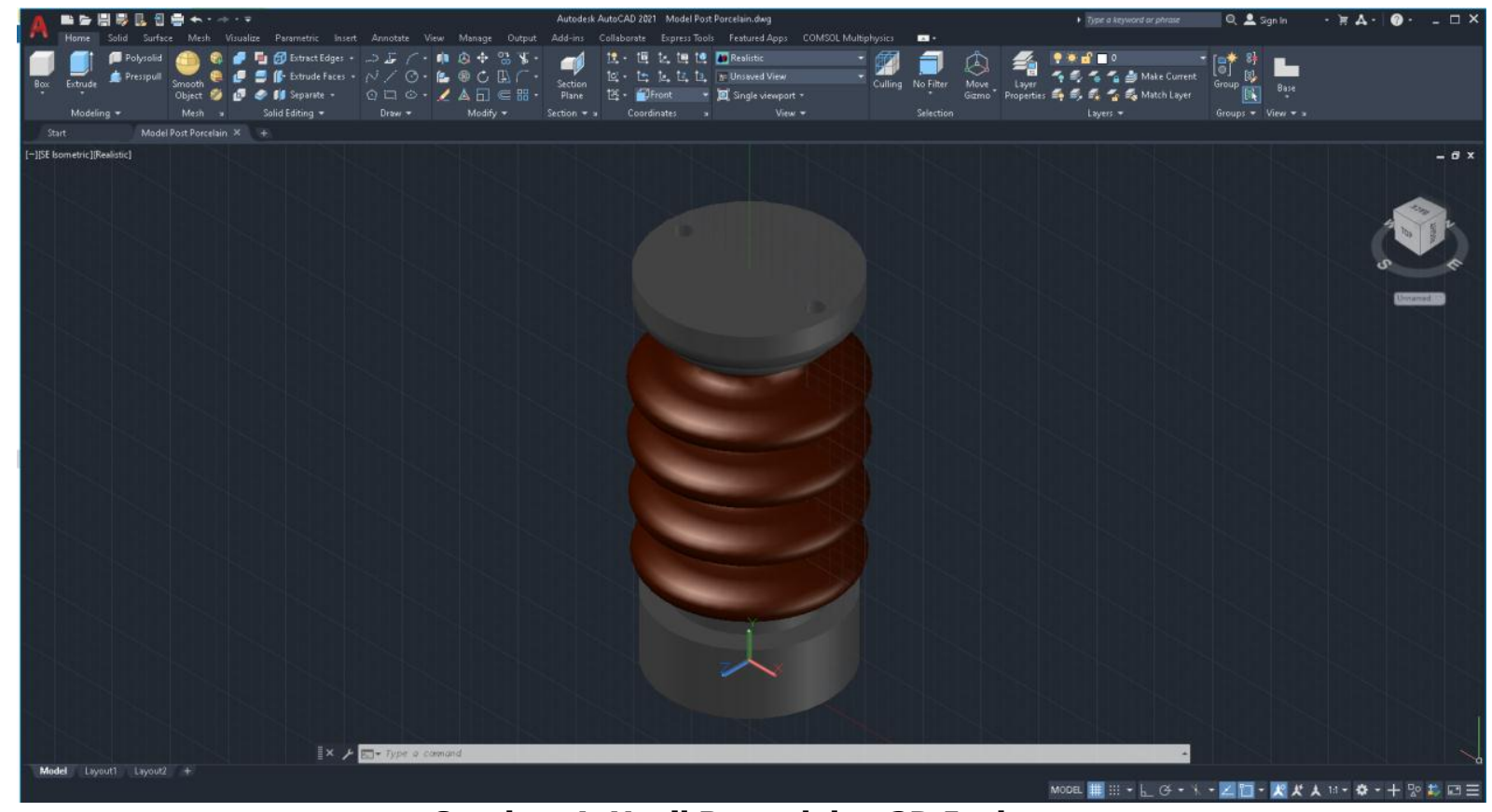

Gambar 4. Hasil Pemodelan 3D Isolator 


\subsection{Software Berbasis Metode Elemen Hingga}

Metode elemen hingga (MEH), kadang-kadang disebut sebagai analisis elemen hingga (FEA), merupakan metode perhitungan dengan pendekatan numerik. Metode perhitungannya adalah dengan menghitung mata jaring kecil yang akan digabungkan menjadi bentuk yang lebih besar untuk digabung. Hasil yang diperoleh bersumber dari nilai estimasi lanjutan terhadap apa yang diasosiasikan dengan bagian mesh, sehingga diperoleh bentuk yang diharapkan. (Suprianto, Munoto, \& Dwinugraha, 2017). Prinsip pokok dari MEH adalah proses diskritisasi, yaitu suatu objek atau area yang dianalisis dibagi menjadi elemen-elemen yang saling terkoneksi, setelah itu dimodelkan sebagai satu dimensi, dua dimensi, atau tiga dimensi (Pratama, 2016).

Untuk langkah-langkah pada software berbasis MEH ini dapat diringkas dalam empat langkah berturut-turut berikut ini (Benguesmia, M'ziou, \& Boubakeur, 2018):

1. Langkah pertama adalah mengekspor geometri tiga dimensi (3D) atau dua dimensi (2D) dari isolator yang telah dibuat pada software berbasis CAD ke software simulasi MEH.

2. Langkah kedua menyangkut definisi sifat listrik dari bahan yang digunakan. Ini terdiri dari mendefinisikan permitivitas relatif $(\varepsilon)$ dan konduktivitas $(\sigma)$ untuk setiap bagian dari isolator. Selain itu juga perlu untuk menentukan kondisi batas yang diterjemahkan ke dalam potensial yang dikenakan pada setiap elektroda (kondisi Dirichlet).

3. Langkah ketiga dikhususkan untuk memecahkan masalah dengan menerapkan metode numerik dan konstruksi sistem persamaan, dan ini dengan memperkenalkan faktor-faktor dari setiap bagian persamaan.

4. Langkah terakhir adalah menyelesaikan masalah dan menampilkan hasil simulasi sebagai distribusi potensial dan medan listrik.

Gambar 5 berikut menunjukkan hasil diskretisasi atau mesh sebagai salah satu tahapan dari proses penyelesaian simulasi berbasis MEH ini. Isolator porselen sebagai objek yang akan dianalisa dipecah menjadi sekumpulan elemen-elemen segitiga. Selanjutnya pada setiap node elemen akan dihitung potensial listriknya. Setelah diketahui besar potensial listrik dari setiap node masing-masing elemen, elemen tersebut digabungkan kembali sehingga didapatkan nilai distribusi potensial listrik dan medan listriknya.

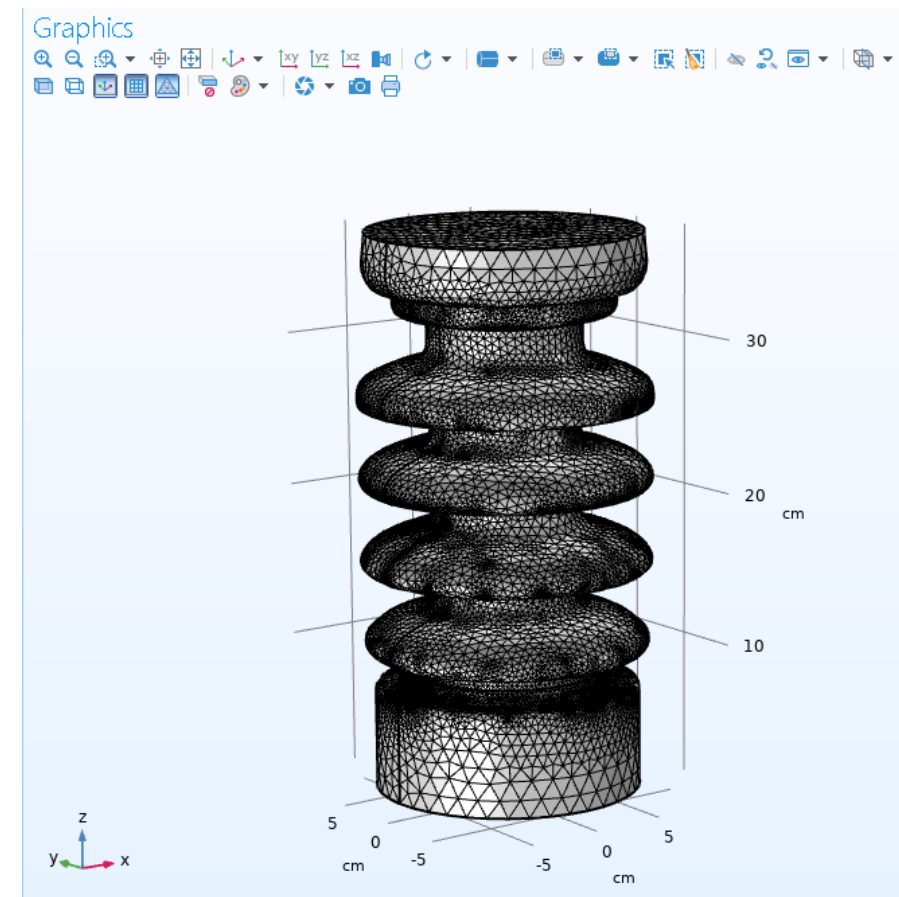

Gambar 5. Hasil Mesh Menggunakan Software Berbasis MEH 


\section{HASIL DAN PEMBAHASAN}

Simulasi berbasis MEH yang dilakukan pada penelitian ini dilakukan dalam model 3D serta 2D. Pada model 3D, besar potensial listrik dan medan listrik dapat terdeteksi dari tiap sisi isolator (sumbu $\mathrm{x}, \mathrm{y}, \mathrm{z}$ ) dengan pola distribusi potensial listrik dan medan listrik yang terlihat hanya pada bagian isolator saja. Sedangkan pada model 2D, besar potensial listrik dan medan listrik hanya didapatkan pada satu sisi saja (dari arah depan saja, sumbu $\mathrm{x}$ dan $\mathrm{z}$ ), tetapi pola distribusi potensial listrik dan medan listriknya dapat dilihat hingga ke domain udaranya (keadaan potensial listrik dan medan listrik pada udara di sekitar isolator). Selain itu, dari hasil simulasi didapatkan pula grafik distribusi potensial listrik dan medan listrik.

\subsection{Hasil Simulasi 3D Isolator}

Gambar 6 menunjukkan hasil simulasi 3D distribusi potensial listrik pada isolator porselen, nilai potensial listrik terlihat terus berkurang dari sumber tegangan menuju ground dengan mengikuti pola kontur isolator yang ada. Potensial listrik maksimum yang terjadi setelah dilakukan simulasi adalah sebesar 16,32 kV.

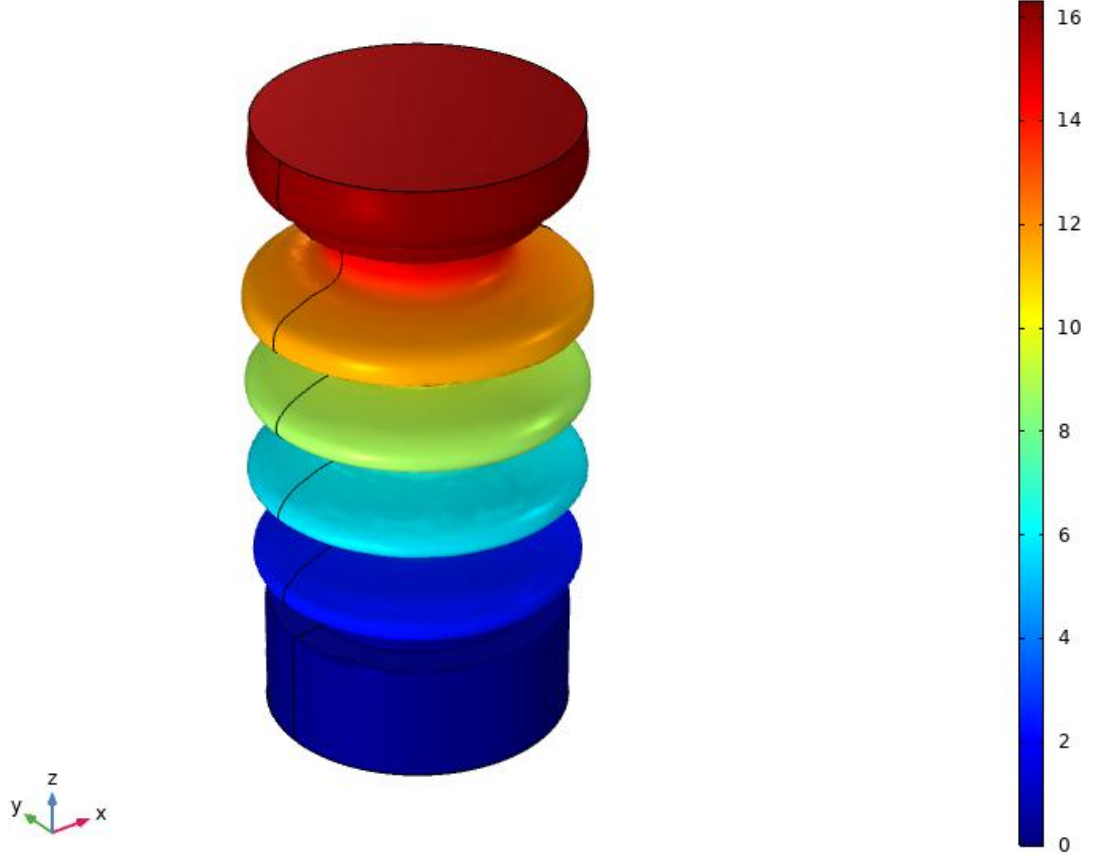

Gambar 6. Hasil Simulasi 3D Distribusi Potensial Listrik Isolator Porselen

Sedangkan Gambar 7 menunjukkan hasil simulasi 3D distribusi medan listrik dengan nilai maksimum medan listriknya terdeteksi mencapai $5,3 \mathrm{kV} / \mathrm{cm}$. Ini menunjukkan bahwa isolator ini memiliki kemampuan yang baik dalam medistribusikan medan listrik sehingga tidak terjadi fenomena corona pada isolator ini, karena medan listrik maksimum tidak melebihi gradien tegangan tembus $30 \mathrm{kV} / \mathrm{cm}$. Warna biru yang lebih cerah pada Gambar 7 menunjukkan bahwa pada daerah tersebut terdapat stress medan listrik yang lebih besar dibandingkan dengan daerah yang lainnya. Daerah tersebut terletak pada titik-titik koneksi isolator dengan konduktor dan koneksi isolator dengan ground. Ditunjukkan dengan adanya bagian berwarna biru muda pada Gambar 7. 

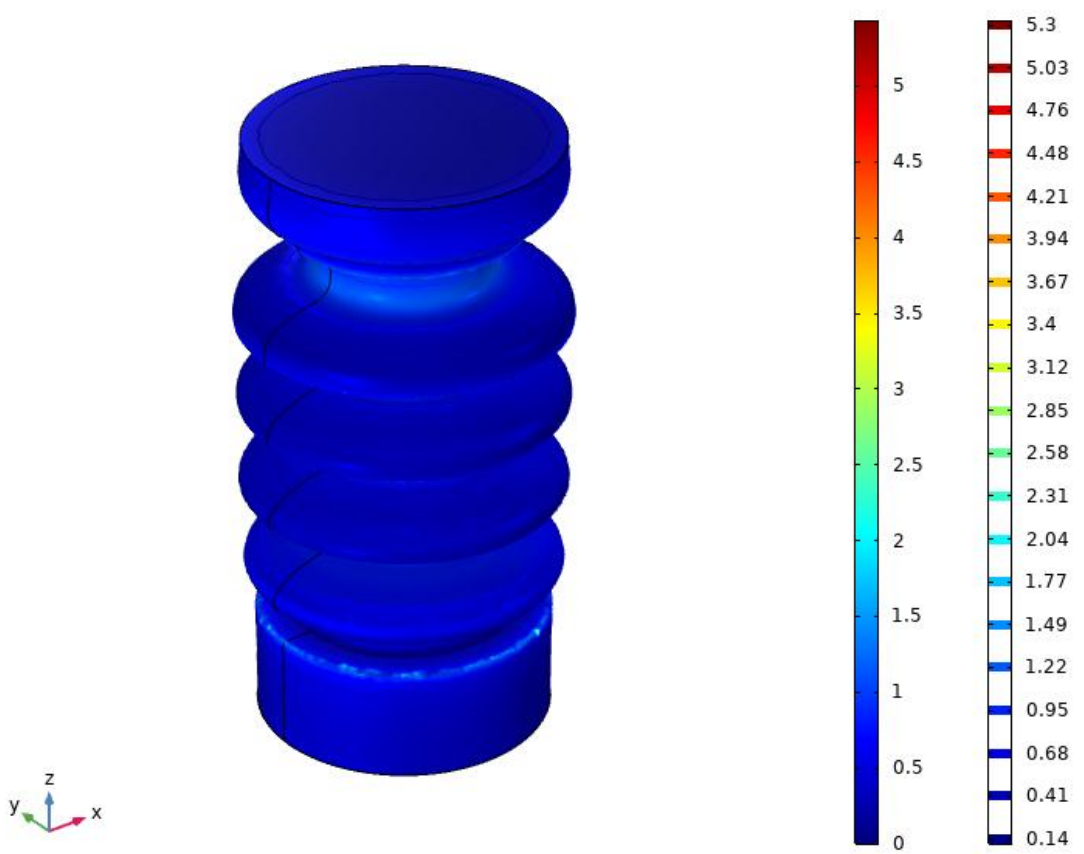

Gambar 7. Hasil Simulasi 3D Distribusi Medan Listrik Isolator Porselen

\subsection{Hasil Simulasi 2D Isolator}

Gambar 8 merupakan hasil simulasi 2D distribusi potensial listrik pada isolator porselen, garis-garis potensial listrik terlihat bergelombang mengikuti kontur sirip. Potensial listrik tertinggi yang ditandai warna merah tua berada di bagian paling atas isolator, menunjukkan bahwa daerah tersebut bersentuhan langsung dengan bagian bertegangan (konduktor). Kemudian pada domain udara, terlihat bahwa udara juga mengisolasi tegangan dengan berkurangnya kontras warna merah pada udara di sekitar konduktor.

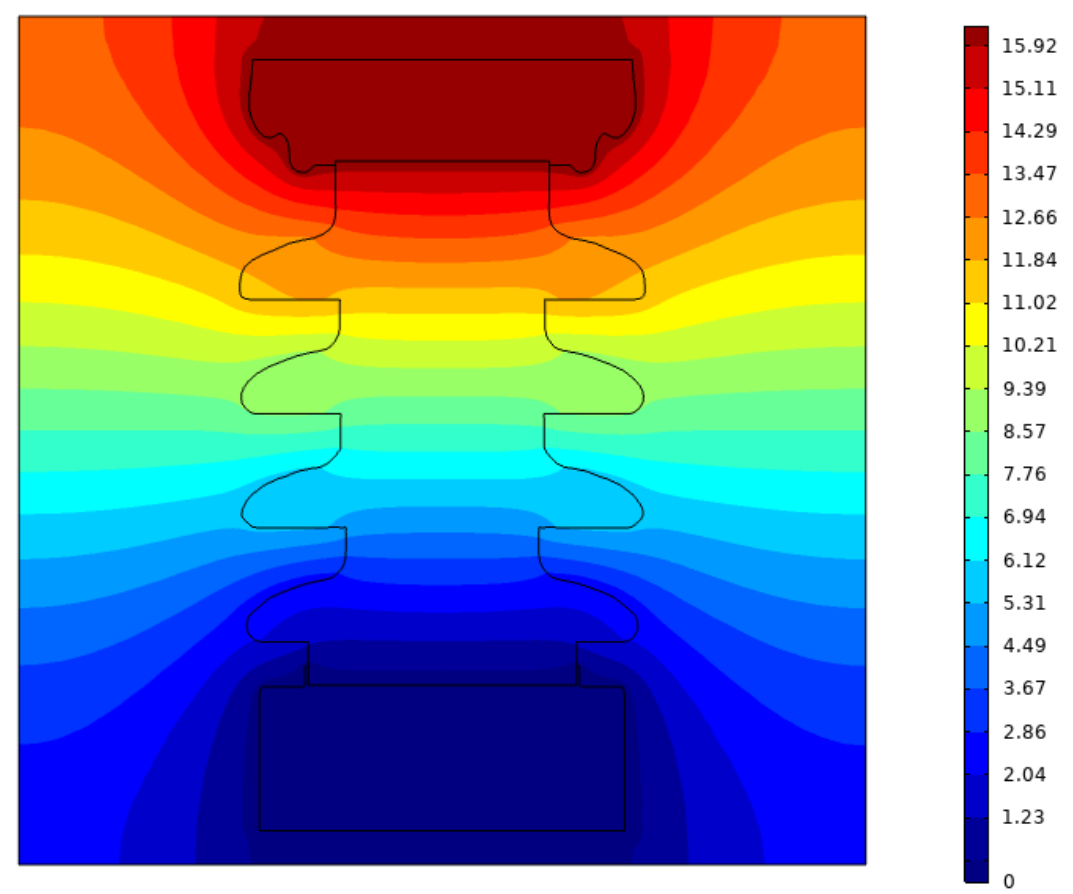

Gambar 8. Hasil Simulasi 2D Distribusi Potensial Listrik Isolator Porselen 
Gambar 9 merupakan hasil simulasi 2D distribusi medan listrik isolator porselen. Selaras dengan hasil simulasi 3D-nya, terlihat bahwa bagian tengah isolator mengalami stress medan listrik yang lebih tinggi dibandingkan dengan bagian sirip-siripnya, ini menunjukkan bahwa daerah sirip berfungsi untuk mendistribusikan medan listrik ke udara. Dibuktikan dengan medan listrik yang lebih tinggi yang terjadi pada domain udara di sekitar sirip-sirip isolator tersebut. Kemudian, semakin menjauhi isolator, medan listrik di udara semakin mengecil dikarenakan udara juga memiliki sifat mengisolasi. Daerah dengan stress medan listrik paling tinggi berada di sambungan antara isolator dengan bagian bertegangan juga dengan bagian ground, ditunjukkan dengan munculnya warna kuning dan merah yang samar. Nilai maksimum medan listrik yang terdeteksi pada simulasi 2D ini hanya mencapai $3,87 \mathrm{kV} / \mathrm{cm}$ dikarenakan simulasi 2D tidak dapat mendeteksi seluruh bagian isolator seperti pada simulasi 3D.

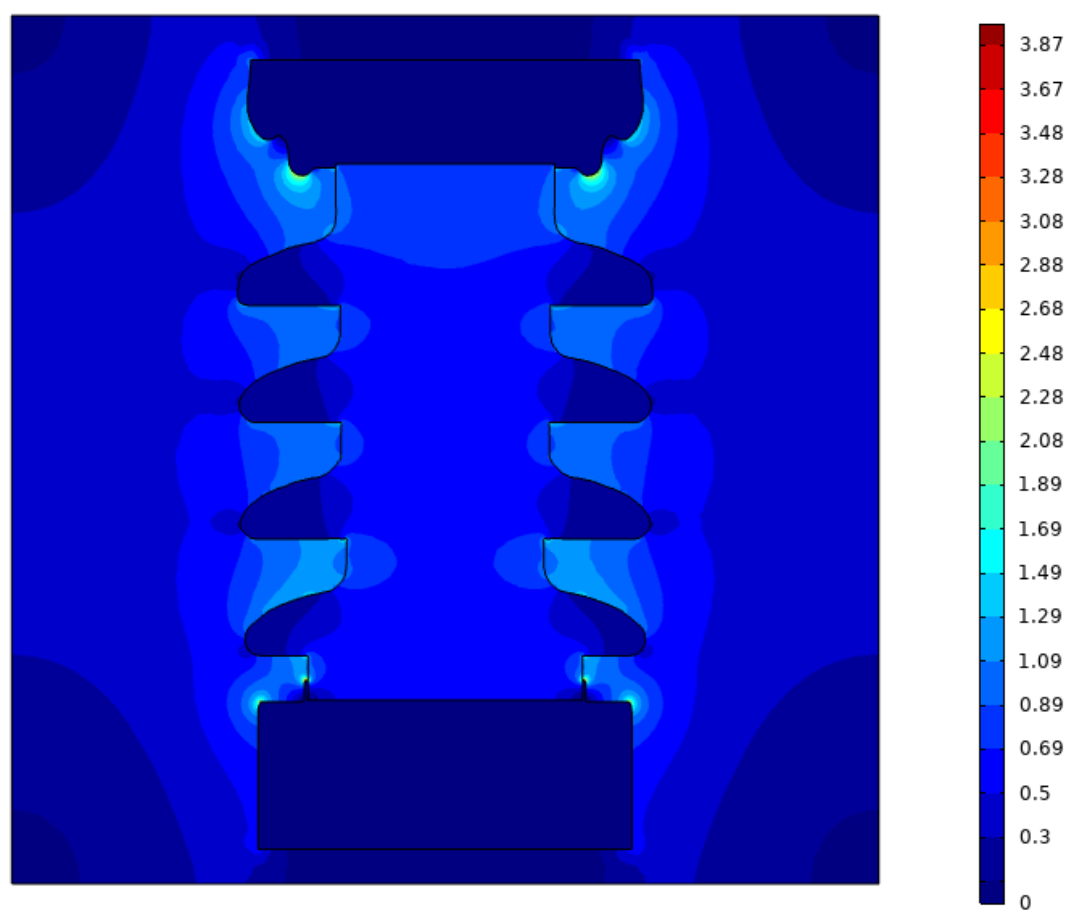

Gambar 9. Hasil Simulasi 2D Distribusi Medan Listrik Isolator Porselen

\subsection{Grafik Distribusi Potensial Listrik dan Medan Listrik}

Sample data untuk grafik diambil dari satu sisi bagian isolator, data diambil di sepanjang permukaan isolator dari bagian atas ke bawah atau disebut arc length. Gambar 10 menunjukkan grafik potensial listrik pada isolator porselen. Dimana sumbu $\mathrm{x}$ yaitu arc length $(\mathrm{cm})$ dibandingkan terhadap sumbu y yaitu potensial listriknya (kV). Pada arc length $0-10 \mathrm{~cm}$ merupakan bagian koneksi antara antara isolator dengan konduktor yang ditunjukkan dengan nilai potensial listrik maksimum sebesar 16,33 kV, sedangkan pada arc length 60-70 $\mathrm{cm}$ merupakan bagian koneksi isolator dengan ground yang ditunjukkan dengan nilai potensial listrik $0 \mathrm{~V}$.

Potensial listrik sepanjang permukaan isolator tedistribusi dengan baik dan mengikuti kontur permukaan dari isolator tersebut, nilai potensial listrik akan semakin turun apabila jarak pengambilan data pada isolator semakin menjauhi sumber tegangan dan semakin mendekati ground. Hal ini menunjukkan bahwa isolasi tegangan yang dilakukan oleh isolator berhasil. 


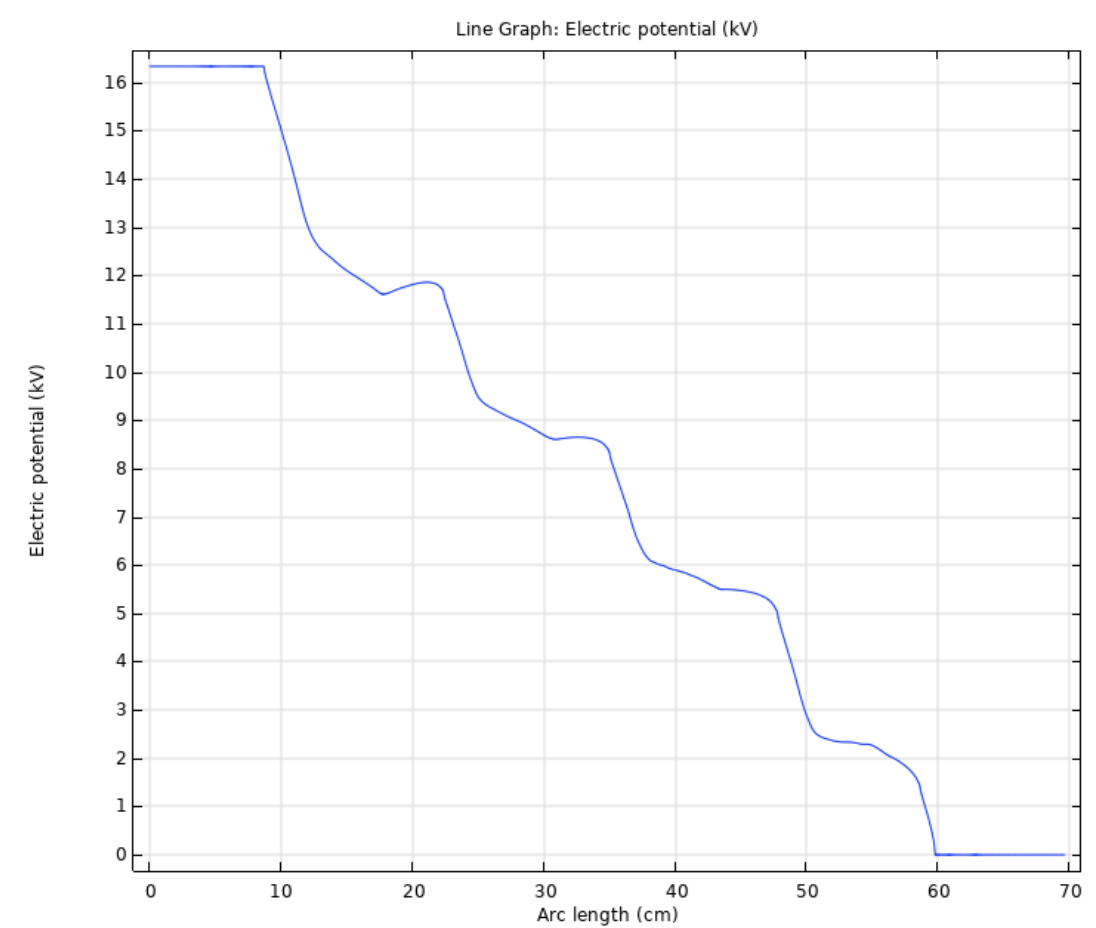

Gambar 10. Grafik Distribusi Potensial Listrik pada Isolator Porselen

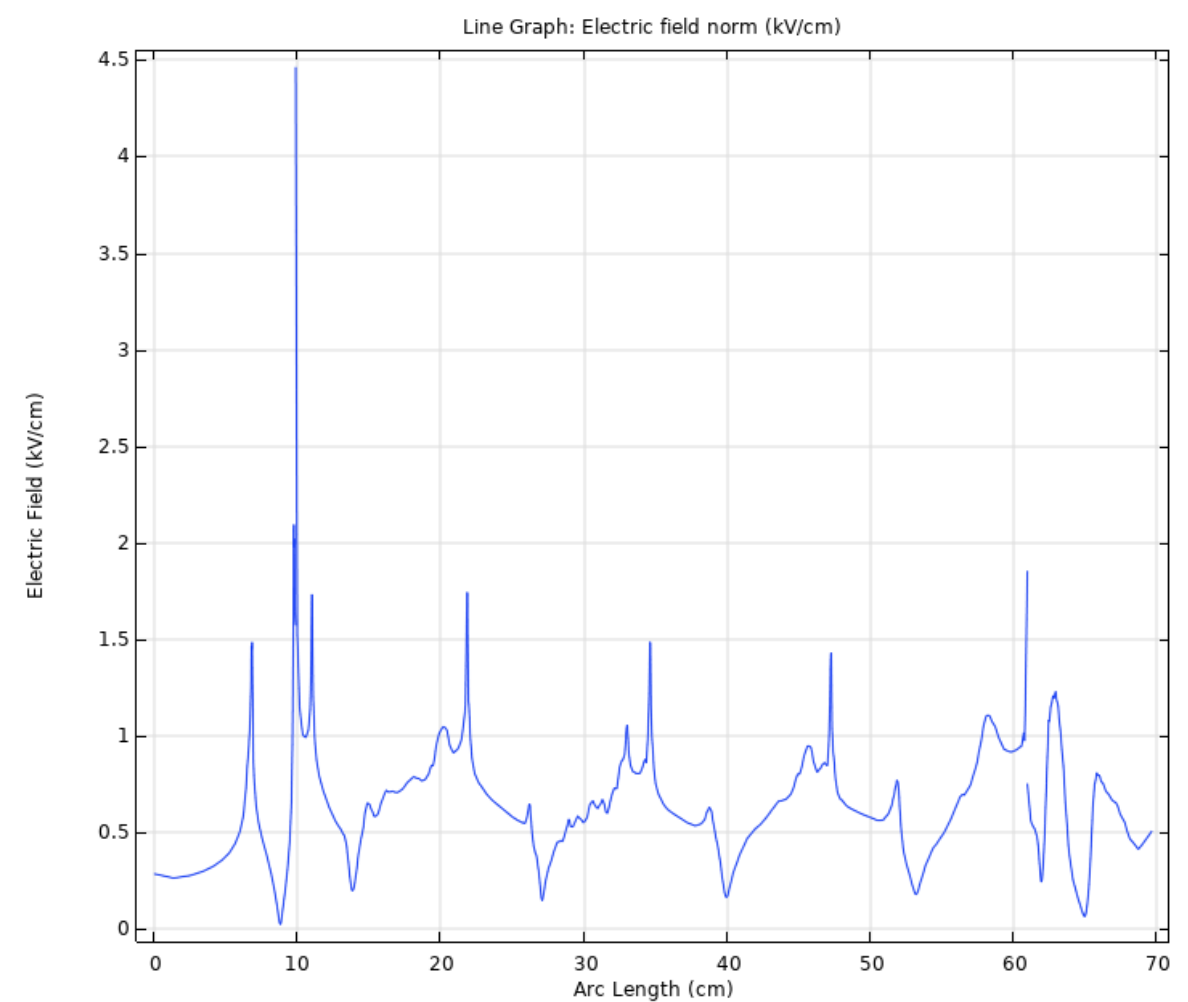

Gambar 11. Grafik Distribusi Medan Listrik pada Isolator Porselen

Gambar 11 menunjukkan grafik medan listrik pada isolator porselen. Dimana sumbu $\mathrm{x}$ yaitu arc length $(\mathrm{cm})$ dibandingkan terhadap sumbu y yaitu medan listriknya (kV). Dari Gambar 10 dan Gambar 11 diatas terlihat bahwa meskipun potensial listrik merupakan salah satu faktor penentu medan listrik, nilai medan listrik tidak selalu berbanding lurus dengan nilai potensial listriknya. Faktor lain seperti kontur isolator juga memiliki pengaruh terhadap pola distribusi 
dan besar medan listriknya. Pada grafik ini, dapat terlihat lebih jelas bahwa distribusi medan listrik terbesar terdapat pada bagian koneksi antara isolator dengan konduktor nilainya mencapai $4,5 \mathrm{kV} / \mathrm{cm}$ serta isolator dengan ground mencapai $1,85 \mathrm{kV} / \mathrm{cm}$. Nilai medan listrik maksimum yang terdeteksi berbeda dengan simulasi 3D dan 2D karena sampel data yang diambil hanya pada satu sisi seperti yang dijelaskan pada awal subbab ini. Medan listrik memiliki sifat yang lebih condong merambah ke area dengan muatan ruang lebih kecil bahkan mendekati nol atau menempuh jalur dengan tahanan kecil. Bagian antara isolator dengan konduktor serta isolator dengan ground terbuat dari besi yang bersifat menghantarkan (tahanan kecil), ini menjelaskan mengapa pada bagian tersebut terjadi distribusi medan listrik yang lebih besar. Medan listrik pada bagian koneksi antara isolator dengan konduktor lebih besar nilainya dibandingkan pada bagian koneksi isolator dengan ground karena memiliki potensial listrik lebih besar dimana potensial listrik merupakan salah satu faktor penentu medan listrik seperti yang dijelaskan pada paragraf sebelumnya.

\section{KESIMPULAN}

Berdasarkan simulasi yang telah dilakukan diperoleh hasil bahwa potensial listrik memiliki pola distribusi dimana semakin menjauhi sumber tegangan pada isolator akan semakin berkurang nilainya. Dengan potensial listrik maksimum sebesar 16,33 kV. Kemudian, pola distribusi medan listrik tidak selalu berbanding lurus dengan distribusi potensial listriknya. Medan listrik maksimum yang terdeteksi adalah sebesar $5,3 \mathrm{kV} / \mathrm{cm}$ sehingga tidak menimbulkan corona. Stress medan listrik yang cenderung lebih tinggi pada isolator terjadi di daerah koneksi antara isolator dengan konduktor mencapai $4,5 \mathrm{kV} / \mathrm{cm}$ serta isolator dengan ground mencapai $1,85 \mathrm{kV} / \mathrm{cm}$, sehingga menunjukkan bahwa hasil simulasi berbasis $\mathrm{MEH}$ ini sesuai dengan standar IEC 60168. Dari hasil-hasil tersebut, isolator porselen $20 \mathrm{kV}$ berjenis post ini dinyatakan memiliki kemampuan yang baik dalam mengisolasi potensial listrik dan mendistribusikan medan listrik serta tidak mengalami fenomena corona karena medan listrik terdistribusikan dengan baik.

\section{DAFTAR RUJUKAN}

Anwar, W. (2019). Pengaruh Endapan Polutan MgCl2 terhadap Tegangan Korona pada Isolator Keramik Tegangan Menengah. Gorontalo: Universitas Negeri Gorontalo.

Benguesmia, H., M'ziou, N., \& Boubakeur, A. (2018). Simulation of the Potential and Electric Field Distribution on High Voltage Insulator Using the Finite Element Method. Diagnostyka, 41-52.

Changfu, X., Chengbo, H., Jiayuan, X., Yunpeng, L., Kaiyuan, Z., \& Shaotong, P. (2017). Influence of Deteriorated Porcelain Insulator on Electric Field and Potential Distribution of Insulators Strings in $110 \mathrm{kV}$ Transmission Lines. IEEE International Conference on Smart Grid and Smart Cities, (pp. 162-166).

Fahmi, D., Yulistya, I. M., Asfani, D. A., \& Afif, Y. (2015). Analisis Distribusi Medan Listrik pada Isolator Gantung Jenis Polimer akibat Pengaruh Kontaminan. Jurnal Nasional Teknik Elektro, 182-189. 
Garinas, W. (2016). Proses Pembuatan dan Pengujian Benda Uji Keramik untuk Bahan Baku Isolator Listrik Keramik Porselen. Majalah IImiah Pengkajian Industri, 173-180.

General Electric Company. (2020, December 20). IEC\& Porcelain Post Insulators for AC and DC Applications. Diambil kembali dari gegridsolutions.com: https://www.gegridsolutions.com/products/brochures/xdge/xdge_iecpostinsulatora4p rint.pdf

Ghifari, R. M., Lazuardi, D., \& Somantri, H. (2017). Optimasi Ketebalan Serat Komposit pada Tabung COPV. Bandung: Universitas Pasundan.

Ogar, V., Bendor, S., \& James, A. (2017). Analysis of Corona Effect on Transmission Line. American Journal of Engineering Research (AJER), 75-88.

Panjaitan, J. S., Sinaga, H. H., \& Purwasih, N. (2014). Analisis Peluahan Sebagian di Udara Menggunakan Metode Elektromagnetik. Jurnal Rekayasa dan Teknologi Elektro, 162177.

Pratama, G. K. (2016). Analisis Pengaruh Kontaminan terhadap Distribusi Medan Listrik pada Isolator Load Break Switch Menggunakan Finite Element Method. Surabaya: Institut Teknologi Sepuluh Nopember.

Pratiwi, A. I. (2013). Mekanisme Flashover untuk Menentukan Kinerja Insulator Polimer yang Terkontaminasi. Makassar: Universitas Hasanuddin.

Rosli, H., Othman, N. A., Jamail, N. A., \& Ismail, M. N. (2017). Potential and Electric Field Characteristics of Broken Porcelain Insulator. International Journal of Electrical and Computer Engineering (IJECE), 3114-3123.

Saadat, H. (2004). Power System Analysis Second Edition International Edition. Singapore: The McGraw-Hill Companies, Inc.

Siemens. (2012). 3FL Silicone Long Rod Insulators for Distribution and Transmission Overhead Power Lines. Erlangen: Siemens AG.

Suprianto, B., Munoto, \& Dwinugraha, A. (2017). Analysis Of Electromagnetic Field On Transmission. World Journal of Research and Review (WJRR), 61-66.

Tobing, B. (2012). Peralatan Tegangan Tinggi Edisi Kedua. Jakarta: Erlangga. 